\title{
NGHIÊN CỨU TÌNH HÌNH VÀ MộT SỐ YẾU TỐ LIÊN QUAN ĐẾN RỐI LOAN LIPID MÁU TRONG BÊNNH VẢY NẾN TẠI BỆNH VIÊ̂N DA LIỄU THÀNH PHỐ CẦ THƠ NĂM 2020
}

\section{TÓM TẮT}

Muc tiêu: Xác định tỉ lệ rối loạn lipid máu và các yếu tổ liên quan trên bệnh nhân vảy nến. Đối tượng và phương pháp: Nghiên cứu mô tả cắt ngang tiến cứu được tiến hành trên 90 bệnh nhân vảy nến điều trị tại Bệnh viện Da liếu Cần Thơ năm 2020. Kết quả: Tỉ lệ rối loạn lipid máu ở bệnh nhân vảy nến là $60 \%$, trong đó rối loan chiếm tỉ lê cao nhất là tăng Triglycerid $(33,3 \%)$, kế đến là giảm HDL chiếm 30\%, tăng Cholesterol toàn phần $(20 \%)$ và sau cùng là tăng LDL-c (12,2\%). Chưa tìm được các yếu tố liên quan làm thay đổi nồng đô lipid máu của bệnh nhân vảy nến mang ý nghĩa thống kê. Kết luận: Tỉ lệ rối loạn lipid máu trên bệnh nhân vảy nến cao nhưng vẫn chưa rõ nguyên nhân phía sau.

Tư khóa: Rối loạn lipid máu, vảy nến.

\section{SUMMARY \\ STUDY OF THE DYSLIPIDEMIA CONDITION AND ITS RISK FACTORS IN PSORIASIS PATIENTS AT CAN THO DERMATO- VENEROLOGY HOSPITAL IN 2020}

Objective: To determine the prevalenceand risk factors of dyslipidemia in psoriasis patient. Subjects and method: This is a prospective cross-sectional descriptive study conducted on 90 psoriasis patients treated at Can Tho Dermatology Hospital in 2020. Results: The prevalence of dyslipidemia in the disease psoriasis was $60 \%$, in which the disorder accounted for the highest proportion was hightriglycerid $(33.3 \%)$, followed by low HDL by $30 \%$, high cholesterol $(20 \%)$ and finally high LDL-C $(12.2 \%)$. However, we have not found any statistically significant risk factors of the disorder in psoriasis patients yet. Conclusion: The incidence of dyslipidemia in psoriasis patients was high, but the reasons behind that were still not clear.

Keywords: Dyslipidemia, psoriasis.

\section{I. ĐĂTT VẤN ĐỀ}

Vảy nến là một bệnh viêm mạn tính qua trung gian miễn dịch rất phổ biến [8]. Trước đây, bệnh vảy nến chỉ được xem là một tình trạng viêm da nhưng hiện nay được biết như là một bệnh viêm có tính hệ thống, giống như viêm

*Bênh viên Đai hoc Y Dước Cần Thơ

Chịu trách nhiệm chính: Huỳnh Văn Bá

Email: bs.ba_fob@yahoo.com.vn

Ngày nhận bài: 5/6/2021

Ngày phản biên khoa học: 22/6/2021

Ngày duyệt bài: 31/7/2021

Phạm Thanh Thảo*, Huỳnh Văn Bá*, Lạc Thị Kim Ngân*, Trần Nguyễn Anh Thư* khớp dạng thấp và bệnh Crohn [8], Gần đây có nhiều nghiên cứu cho thấy mối liên quan giữa vảy nến và bệnh tim mạch, theo đó vảy nến là yếu tố nguy cơ độc lập của các bệnh lý như đột quy, bệnh mạch vành... [8]. Trong khi đó, rối loạn lipid máu có vai trò rất quan trong trong quá trình xơ vữa động mạch và là một trong những yếu tố nguy cơ tim mạch chính yếu. Đã có nhiều nghiên cứu trên bệnh nhân vảy nến cho thấy sự biến đổi nồng độ các lipid gây xơ vữa như tắng triglyceride, cholesterol toàn phần, LDL-C (low-density lipoprotein cholesterol), VLDL-C(very-low-density lipoprotein cholesterol), và giảm nồng độ $\mathrm{HDL}-\mathrm{C}$ (high-density lipoprotein cholesterol) [5], [7]. Với mong muốn thực hiện nghiên cứu nhẳm đánh giá nồng độ lipid máu trên bệnh nhân vảy nến, từ đó giúp ích trong viêc tầm soát và điêuu trị sớm rối loan lipid máu nhằm phòng ngừa xơ mõ động mạch trên bệnh nhân vảy nến trên bệnh nhân vảy nến, cải thiện tiên lượng sống và chất lượng cuộc sống cho bệnh nhân, chúng tôi tiến hành đề tài này với những mục tiêu sau:

- Xác định tỷ lể rối loạn lipid máu của bênh nhân vảy nến điều trị tại Bệnh viện Da Liễu Thành Phố Cần Thơ năm 2020.

- Mô tả một số yếu tố liên quan đến rối loạn lipid máu của bệnh nhân vảy nến điều trị tại Bệnh viện Da Liễu Thành phố Cần Thơ năm 2020.

\section{II. ĐỐI TƯỢNG VÀ PHƯƠNG PHÁP NGHIÊN CỨU}

2.1. Đối tượng nghiên cứu: Tất cả bệnh nhân bị bệnh vảy nến đến khám và điều trị tại Bệnh viện Da liễu Thành phố Cần Thơ năm 2020.

Tiêu chuẩn chọn mấu:

- Chọn mẫu nghiên cứu là những bệnh nhân được chẩn đoán bệnh vảy nến điều trị tại Bệnh viện Da liễu Thành Phố Cần Thơ. Chẩn đoán chủ yểu dựa vào lâm sàng, cụ thể thương tổn là mảng hồng ban tróc vảy có $\geq 1$ trong các tính chất gợi ý: phân bố đối xứng; ở mặt duỗi chi; dấu hiệu Auspitz, thương tổn giới hạn rõ, vảy trắng bạc.

- Bệnh nhân chấp nhận tham gia nghiên cứu.

Tiêu chuẩn loại trừ:

- Người có bệnh gây tăng lipid máu thứ phát như: nhược giáp, tiểu đường, hội chứng thận hư, 
suy thận mạn, bênh mô liên kết.

- Có đang sử dụng các thuốc: ức chế beta, thiazide, corticosteroid, retinoids, cyclosporine, và những thuốc hạ lipid máu.

- Chỉ số khối cớ thể (BMI) >30.

- Có thai hoặc đang cho con bú.

\subsection{Phương pháp nghiên cứu}

Thiết kế nghiên cứu: Phương pháp nghiên cứu mô tả cắt ngang tiến cứu.

Cỡ mẫu và phương pháp chọn mẫu: Áp dụng công thức ước lượng một tỷ lệ với mức tin cậy $95 \%$, sai số cho phép $10 \%$ và tỷ lệ rối loạn lipid máu tham khảo theo Salihbegovic E. M. và cộng sự (2015) là 62,85\% [15], cõ̃ mẫu ước tính được là 90 bệnh nhân.

2.3. Nội dung nghiên cứu: - Đặc điểm chung của đối tượng nghiên cứu: tuổi, giới.

- Đặc điểm lâm sàng của bệnh vảy nến: tuổi khởi phát, thời gian mắc bệnh, triệu chứng cơ năng, tiên sử gia đình, vị trí tổn thương hiện tại, thể lâm sàng, độ nặng của bệnh theo PASI, diện tích vùng da bệnh.

- Tình trạng rối loạn lipid máu: nồng độ triglyceride (TG) máu, nồng độ cholesterol toàn phần (Cholesterol TP) máu, nồng độ LDL-C, nồng độ HDL-c. Bệnh nhân được xem là có rối loạn lipid máu khi có ít nhất một trong các tiêu chuẩn sau: Cholesterol TP $>6,2 \mathrm{mmol} / \mathrm{l}, \mathrm{TG} \geq 2,26$ $\mathrm{mmol} / \mathrm{l}$, LDL-C $\geq 4,13 \mathrm{mmol} / \mathrm{l}, \mathrm{HDL}-\mathrm{c}<1,03$ $\mathrm{mmol} / \mathrm{l}$ (theo ATP III, 2001).

- Các yếu tố liên quan đến rối loạn lipid máu: tiền sử gia đình, huyết áp (huyết áp tâm

thu và huyết áp tâm trương), cân nă̆ng, chiều cao, BMI, hoạt động thể lực, hút thuốc lá, uống rượu và chế độ ăn giàu chất béo.

2.4. Phương pháp thu thập và xử lý số liệu

- Hỏi bênh, thăm khám lâm sàng theo phiếu thu thập số liệu

- Xét nghiệm định lượng nồng độ lipid máu

- Số liệu được quản lý và xử lý bằng phần mềm Microsoft Excel 2016 và SPSS 18.0. Làm sạch số liệu trước khi tiến hành phân tích kết quả.

\section{KẾT QUẢ NGHIÊN CứU}

Trong 90 đối tượng nghiên cứu, nam giới chiếm $62,2 \%$ trong khi nữ chiếm $37,8 \%$, tỷ lệ nam/nữ xấp xỉ $3 / 2$. Độ tuổi trung bình là $43,4 \pm$ 15,7 , dao động từ người trẻ nhất là 9 tuổi đến cao nhất là 80 tuổi. Trong đó, nhóm tuổi chiếm tỷ lệ cao nhất là $35-60$ tuổi $(52,2 \%)$.

Các bệnh nhân khởi phát bệnh muộn sau 30 tuổi chiếm đa số, lên đến $72,2 \%$ so với nhóm khởi phát sớm chỉ 27,8\%. Độ tuổi khởi phát sớm nhất là 6 tuổi, lớn nhất 75 tuổi, trung bình 37,81 \pm 12 ,9. Thời gian bệnh dao động từ 2 tháng đến 35 năm, trung bình khoảng 6 năm. Những người mắc bệnh dưới 5 năm chiếm tỷ lệ cao nhất $(55,6 \%)$.

Về lâm sàng, tất cả các bệnh nhân đều có triệu chứng ngứa. Vị trí tương tổn thường gặp nhất là ở vùng chi trên $(81,1 \%)$ và than mình $(77,8 \%)$. Đa số vẫn là vảy nến thông thường (83,3\%), các dạng khác như vảy nến mủ, đỏ da toàn thân, viêm khớp vảy nến chỉ chiếm tỷ lệ nhỏ, lần lượt là $7,8 \% ; 6,7 \%$ và $2,2 \%$. Diện tích thương tổn tính theo BSA trung bình là $28,64 \%$

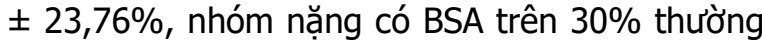
gặp nhất với tỷ lệ 38,9\%. Phân độ nặng của bệnh theo thang điểm PASI cho thẩy nhóm có mức độ trung bình chiếm tỷ lệ cao nhất $(48,9 \%)$ kế đến là nhóm nhẹ với tỷ lệ $38,9 \%$ và cuối cùng là nhóm nặng chiếm 12,2\%.

Bảng 1. Tý lệ rối loạn của các loại lipid máu trên bệnh nhân vảy nến

\begin{tabular}{|c|c|c|}
\hline $\begin{array}{c}\text { Loại rối loạn lipid } \\
\text { máu }\end{array}$ & $\begin{array}{c}\text { Tân số } \\
\text { (n) }\end{array}$ & $\begin{array}{c}\text { Tỷ lế } \\
\text { (\%) }\end{array}$ \\
\hline $\begin{array}{c}\text { Rối loạn lipid máu nói } \\
\text { chung }\end{array}$ & 54 & $60 \%$ \\
\hline Tăng Cholesterol TP & 18 & $20 \%$ \\
\hline Tăng TG & 30 & $33.3 \%$ \\
\hline Tăng LDL-C & 11 & $12,2 \%$ \\
\hline Giảm HDL-c & 27 & $30 \%$ \\
\hline Lipid máu bình thường & 36 & $30 \%$ \\
\hline
\end{tabular}

Có đến $60 \%$ bệnh nhân có rối loạn lipid máu, chiếm gần $2 / 3$ tổng số đối tượng nghiên cứu. Trong số này, dạng rối loạn phổ biến nhất là tăng TG $(33,3 \%)$, kế đến là giảm HDL-c $(30 \%)$, tăng Cholesterol TP (20\%) và thấp nhất là tăng LDL-c (12,2\%).

Khảo sát về các yếu tố liên quan đến tình trạng này, không tìm thấy sự liên quan giữa tỷ lệ rối loạn lipid máu và giới, tuổi, hoạt động thể lực, thói quen hút thuốc lá, uống rượu bia, huyết áp, BMI hay chễ độ ăn. Các yếu tố về mặt lâm sàng như tuổi khởi phát, thời gian mắc bệnh, tiên sử gia đình, thể bệnh hay mức độ nặng phân theo PASI và BSA cũng không ảnh hưởng đến tình trạng tăng lipid.

\section{BÀN LUẬN}

Tuổi trung bình của 90 bệnh nhân nghiên cứu là $43,4 \pm 15,7$, trong đó nhóm tuổi 35 - 60 chiếm tỷ lệ cao nhất $(52,2 \%)$. Kết quả này tương tự với nghiên cứu trước đây của Trương Lê Anh Tuấn (2012) nhưng thấp hơn tuổi trung bình trong nghiên cứu của Trương Thị Mộng Thường (2012) là 45,3. Nói chung, tuổi trung bình của bệnh nhân vảy nến trong những nghiên cứu nói 
trên khoảng 40, trong đô tuổi lao đông chính của xã hội. Bệnh vảy nến không chỉ tác động trực tiếp lên bản thân bệnh nhân và gia đình mà còn ảnh hưởng đến nền kinh tế xã hội [3], [4].

Về giới, nam chiếm $62,2 \%$ và nữ chiếm $37,8 \%$. Tỷ lệ nam/nữ là xấp xỉ $3 / 2$, kết quả này tương tự với Trương Lê Anh Tuấn (2012) và Trương Thị Mộng Thường (2012)[3], [4].

Nghiên cứu của chúng tôi bao gồm tất cả các thể lâm sàng của bệnh vảy nến, trong đó thể mảng chiếm tỷ lệ cao nhất $(83,3 \%)$, các thể còn lại lần lượt là vảy nến thể mủ $(7,8 \%)$, vảy nến đỏ da toàn thân $(6,7 \%)$, viêm khớp vảy nến $(2,2 \%)$. Vảy nến thể mảng cũng chiếm tỷ lệ cao nhất trong nghiên cứu của Trương Thị Mộng Thường với 74,6\%, Nguyễn Trong Hào là 78,1\% và nghiên cứu của Trương Lê Anh Tuấn với $80 \%$. Tỷ lệ này theo Fitzpatrick thậm chí còn cao hơn nữa, lên đến $90 \%$ [1], [4].

Vảy nến thông thường chiếm tỷ lệ cao nhất nên được nghiên cứu nhiều hơn cả về sinh bênh học, phương pháp điều trị và cả cách đánh giá mức độ bệnh thông qua chỉ số PASI và BSA. Trong số 75 bệnh nhân vảy nến mảng của chúng tôi, chỉ số PASI trung bình là 13,58 , với mức độ trung bình chiếm tỷ lệ cao nhất (48,9\%) kết quả này tương tự với nghiên cứu của Nguyễn Tất Thắng. Tuy nhiên, tỷ lệ này khác với nghiên cứu của Trương Lê Anh Tuấn và Nguyễn Trọng Hào là mức độ nhe chiếm tỷ lệ cao nhất (lần lượt là $65 \%$ và $58 \%$ ).

Về tình trang rối loạn lipid máu, tỷ lệ nói chung trên các đối tượng nghiên cứu là $60 \%$, trong đó tăng Triglycerid $(33,3 \%)$ chiếm tỷ lệ cao nhất, kế đến là do giảm HDL-c chiếm $30 \%$ và thấp nhất là do tăng LDL-c $(12,2 \%)$.

Theo Daudén E (2013) tỷ lệ rối loạn lipid máu trên bệnh nhân vảy nến thay đổi theo từng nghiên cứu, dao động từ 6,4-50,9\%. Theo Wu Y. và cS (2008) tiến hành nghiên cứu trên 1.127 bệnh nhân vảy nến và 1.127 người nhóm chứng cho thấy tỷ lệ đái tháo đường, tăng huyết áp, tăng lipid máu ở bệnh vảy nến có tỷ lệ các yếu tố nguy cơ tim mạch và những bệnh lý khác cao hơn so với người không bệnh vảy nến nhân vảy nến cao hơn nhóm chứng. Với kết quả của nghiên cứu lớn này, các tác giả khẳng định bệnh nhân vảy nến có tỷ lệ các yếu tố nguy cơ tim mạch và những bệnh lý khác cao hơn so với người không bệnh vảy nến [5]. Một nghiên cứu khác của Salihbegovic EM (2015) trên 70 bệnh nhân vảy nến người Bosnia và Herzegovina cũ̉ng cho tỷ lệ rối loan lipid máu là $62,9 \%$. Nghiên cứu nói trên có tỷ lệ rối loạn lipid máu xấp xỉ với tỷ lệ trong nghiên cứu của chúng tôi (60\%).

Tuy nhiên, một nghiên cứu cắt ngang của Jamil A (2014) trên 120 bệnh nhân vảy nến người Pakistan lại cho thấy tỷ lê rối loạn lipid máu thấp hơn là $55,8 \%$. Nói chung viêc so sánh tỷ lệ rối loạn lipid máu trên bệnh nhân vảy nến giữa các nghiên cứu chỉ mang tính tương đối vì tiêu chuẩn định nghĩa rối loạn lipid máu không thống nhất giữa các tác giả, cũng như khác biệt về chủng tộc, tập quán ăn uống [6].

Về các yếu tố liên quan, chúng tôi chưa tìm ra được sự khác biệt mang ý nghĩa thống kê giữa các nhóm đối tượng phân theo tuổi, giới, hoat động thể lực, thói quen hút thuốc, rượu bia, chế độ ăn hay BMI. Các yếu tố lâm sàng liên quan đến vảy nến khác như tuổi khởi phát, thời gian mắc bệnh, tiền sử gia đình, thể lâm sàng hay mức độ nặng của bệnh phân theo BSA và PASI cũng không cho thấy làm thay đổi tỷ lệ rối loạn lipid máu của bệnh nhân. Do đó, vân chưa thể đưa ra được một dự đoán về các lý do có thể góp phần gây tăng nặng hơn sự rối loạn lipid máu trên bệnh nhân vảy nến.

\section{KẾT LUÂN}

- Các đối tượng nghiên cứu có độ tuổi khởi phát trung bình là 37,81 . Trong các thể lâm sàng: vảy nến thông thường chiếm tỷ lệ cao nhất, các thể còn lại lần lượt là vảy nến đỏ da toàn thân, vảy nến mủ, viêm khớp vảy nến. Vị trí thương tổn: chi trên, ở thân mình, chi dưới, vùng da đâu. Trung bình BSA là 28,64, nhóm BSA nặng có tỷ lệ cao nhất. Tính theo chỉ số PASI: đa số có độ nặng trung bình.

- Tỷ lệ bệnh nhân vảy nến có rối loạn lipid máu là $60 \%$, trong đó: tăng TG chiếm tỉ lệ cao nhất, kế đến là giảm HDL-c, tăng Cholesterol TP và tăng $L D L-c$. Chưa tìm được yếu tố liên quan làm ảnh hưởng đến tỷ lệ rối loạn lipid máu của bệnh nhân.

\section{TÀI LIÊU THAM KHẢO}

1. Nguyễn Trọng Hào \& Trân Hậu Khang (2016), "Nghiên cứu rối loan lipid máu trên bệnh nhân vảy nến", Tap chí Y học Thực hành, số 11/2013̆, trang 30-31.

2. Lê Minh Phúc Nguyến Tất Thắng (2012) "Nồng độ lipid máu trên bệnh nhân vảy nến tại bệnh viện Da Liễu Thành phố Hồ Chí Minh", Tạp chí Y học TP Hồ Chí Minh, 16(1), 260-268.

3. Lê Ngọc Diệp Trương Thị Mộng Thường (2012), "Chất lượng cuốc sống của bênh nhân vảy nến đến điều trị tại bệnh viện Da Liểu TP.HCM từ 01/9/2010 đến 30/4/2011", Tap chí Y học TP. Hồ Chí Minh, tập 16(phụ bản số 1), tr 284-292.

4. Trương Lê Anh Tuấn và Lê Ngọc Diệp (2012), "Mối liên quan giữa bệnh vảy nến và hội chứng chuyển hóa", 268-274. 
5. Daudén E, Castañeda S \& Suárez C et al (2013), "Clinical practice guideline for an integrated approach to comorbidity in patients with psoriasis", J Eur Acad Dermatol Venereol, 27, 1387-1404.

6. Evaluation Expert Panel on Detection, and Treatment of High Blood Cholesterol in Adults (Adult Treatment Panel III) (2002), "Third Report of the National Cholesterol Education Program (NCEP) Expert Panel on Detection, Evaluation, and
Treatment of High Blood Cholesterol in Adults (Adult Treatment Panel III) final report", Circulation, 106(3143-3421

7. Garshick MK \& Kimball AB (2015), " Psoriasis and the life cycle of persistent life effects", Dermatol Clin; 3, 25-39.

8. Grozdev I, Korman N \& Tsankov N (2014), "Psoriasis as a systemic disease", Clinics in Dermatology, 32, 343-350.

\title{
ĐÁNH GIÁ KẾT QUẢ CHUYỂN THẦN KINH XI CHO THẦN KINH TRÊN VAI TRONG ĐIỀU TRI LIÊTT ĐÁM RỐI CÁNH TAY Ở NGƯỜII LỚN
}

\author{
Đào Văn Giang*, Trần Thị Thanh Huyền*, Nguyễn Hồng Hà*
}

\section{TÓM TẮT}

Mục tiêu: Phẫu thuật chuyển thần kinh XI cho thần kinh trên vai để phục hồi chức năng của vai. Đối tượng và phương pháp: Nghiên cứu được thực hiện trên 62 bệnh nhân bị liệt ĐRTKCT được chuyển thần kinh XI cho thần kinh trền vai tai Bênh viên Viêt Đức trong thời gian từ 1/2016 đến 12/2020. Phương pháp nghiên cứu hồi cứu, mô tả cắt ngang. Kết quả: 62 bệnh nhân trong đó tỉ lệ nam/nữ: 61/1, tuổi từ 1856 tưổi, trung bình $27,5 \pm 7,9$ tuổi. Nguyên nhân chủ yễu do tại nạn giao thông $(90,3 \%)$. Thời điểm phẫu thuật chủ yếu là trước 6 tháng. Kết quả phục hồi dạng vai rất tốt ở 6,67\% các trường hợp, phục hồi dạng vai $30-120$ độ đạt $86,67 \%$. Phục hồi xoay ngoài của vai đạt $51,12 \%$. Kết luận: Việc chuyển thần kinh XI cho thần kinh trên vai nhằm phục hồi động tác dang vai và xoay ngoàilà một lựa chọn hữu ích và có giá trị trong điều trị liệt đám rối thần kinh cánh tay

Từ khóa: Liệt đám rối thần kinh cánh tay, thần kinh XI, trên vai

\section{SUMMARY}

ACCESSORY NERVE TRANSFER TO SUPRASCAPULARIS NERVE FOR RECONSTRUCTION OF SHOULDER FUNCTION

Purpose: Accessory nerve transfer to suprascapularis nerve for reconstruction of shoulder fuction. Material and method: 62 patients with traumatic brachial plexus injuries underwent surgical reconstruction with accessory to suprascapular nerve transfers. Method study is retrospective, cross-section study. Results: 62 patients, ratio male/female: 61/1, range of age from 18 to 56 years old. Average of age is $27,5+/-7,9$ years. The waiting time before surgery 6 monthsis the most common. Abduction shoulder recovery $>120$ degree was $6,67 \%$, from $30-120$ was $86,67 \%$. Recovered active external rotation of over 30 degree was $51,12 \%$. Conclusion: In brachial plexus

*Bênh viên Hữu nghi Việt Đức

Chịu trách nhiệm chính: Đào Văn Giang

Email: dr.dzang@gmail.com

Ngày nhận bài: $27 / 6 / 2021$

Ngày phản biên khoa học: $2 / 8 / 2021$

Ngày duyệt bài: $22 / 8 / 2021$ injury, using the spinal accessory nerve for transfer to the suprascapular nerve is reliable and provides some recovery of abduction for a large majority of patients.

Keywords: Spinal accessory nerve; brachial plexus; nerve transfer; nerve grafting; suprascapular nerve.

\section{I. ĐĂTT VẤN ĐỀ}

Tổn thương đám rối thần kinh cánh tay (ĐRCT) do chấn thương khá thường gặp, gây ra tình trạng tổn thương chức năng nghiêm trọng và hay gặp ở người trong độ tuổi lao động. Việc điều trị chấn thương đám rối thần kinh cánh tay cần phối hợp của nhiều kĩ thuật từ giai đoạn can thiệp về phẩu thuật thần kinh, giai đoạn chuyển gân, chuyển cơ, đóng cứng các khớp [4]. Phẫu thuật tái tạo lại chức năng của vai là ưu tiên hàng đầu ở những bệnh nhân tổn thương toàn bộ đám rối thần kinh cánh tay. Cách tiếp cận phổ biến nhất để tái tạo lại chức năng của vai là chuyển thần kinh XI (thần kinh phụ) cho thần kinh trên vai. Trên thế giới - nhìn lại y văn và lịch sử về chuyển thần kinh điều trị tổn thương ĐRCT được phát triển từ năm 1994, tác giả Oberlin và cộng sự lần đầu tiên đề xuất phương pháp chuyển một phần TK trụ cho TK cơ nhị đầu để làm gấp khuỷu (Oberlin I). Năm 2003, Leechavengvongs và cs thực hiện chuyển nhánh TK đầu dài cơ tam đầu cho nhánh trước TK mũ, đồng thời chuyển TK XI cho TK trên vai để phuc hồi dạng và xoay ngoài khớp vai. [6]. Tại Việt Nam, 2005 tác giả Võ Văn Châu đã thực hiện chuyển thần kinh XI cho thần kinh cơ bì qua đoạn ghép thần kinh hiển cho 57 bệnh nhân [1]. Nguyễn Việt Tiến [2], tác giả thực hiện phẫu thuật chuyển ghép TK từ rễ C7 bên đối diện cho TK cơ bì và TK giữa qua đoạn ghép là TK trụ gập đôi, có nối mạch nuôi để điều trị tổn thương hoàn toàn $Đ R C T, \ldots$

Tại Bệnh viện Việt Đức, trong những năm gần đây đã ứng dụng kỹ̃ thuật vi phẫu trong điều trị liệt đám rối thần kinh cánh tay. Trong đó có 